\title{
Prognostic significance of ventricular function and late gadolinium enhancement on CMR in symptomatic patients with scleroderma
}

\author{
Arun Natarajan ${ }^{1 *}$, David Dobarro², Claire E Raphael ${ }^{1}$, Arun J Baksi ${ }^{1}$, Heiko Kindler ${ }^{1}$, Raad Mohiaddin ${ }^{1}$, \\ Dudley Pennell ${ }^{1}$, Benjamin Schreiber ${ }^{2}$, Sanjay K Prasad ${ }^{1}$ \\ From 16th Annual SCMR Scientific Sessions \\ San Francisco, CA, USA. 31 January - 3 February 2013
}

\section{Background}

Cardiac involvement is a leading cause of morbidity and premature mortality in patients with scleroderma. Identification of this offers the opportunity for earlier and more stratified therapeutic intervention. Published data on the prognostic significance of left and right ventricular impairment and myocardial fibrosis in this cohort are limited. The study objective was to determine the prevalence and prognostic significance of abnormalities on cardiovascular magnetic resonance (CMR) in patients with scleroderma who have breathlessness and/or other cardiac symptoms.

\section{Methods}

This is a retrospective longitudinal study of 126 consecutive patients with confirmed scleroderma and cardiac symptoms, who had undergone CMR. Completed scans were available in 124 of these. All scans were performed at 1.5 Tesla (Siemens Sonata or Avanto). Thinned myocardium was defined as thickness $<4 \mathrm{~mm}$, right ventricular hypertrophy defined as thickness $>5 \mathrm{~mm}$. The presence of left ventricular (LV) or right ventricular (RV) dilatation was defined as an increase in indexed LV or RV volumes compared to previously published normal ranges. Late gadolinium enhancement (LGE) was defined as an area of clearly increased signal intensity confirmed on phase swapping. All scans were analysed by two independent operators. All cause mortality was determined from review of hospital records and the

${ }^{1}$ CMR Unit, Royal Brompton Hospital, London, UK, London, UK

Full list of author information is available at the end of the article national summary care database. A Cox proportional hazards model was used to determine predictors of mortality (IBM SPSS 19, USA).

\section{Results}

Demographic data and CMR findings are shown in Table 1. Mean age was 55 (range 19 to 82 ) years, $45 \%$ were male and $81 \%$ had at least one cardiovascular abnormality on the scan. Significant LV dysfunction (ejection fraction $<45 \%$ ) was evident in $12 \%$ of patients and reduction in RV ejection fraction in $20 \%$ of patients. Myocardial fibrosis by LGE was found in $21 \%$ of patients (Table 1). The number of patients with 1,2 or 3 cardiovascular abnormalities on CMR were 13\%, 13\% and $10 \%$ respectively. In total, $46 \%$ of the patients had 4 or more abnormalities. There were 21 deaths during the follow-up period. CMR predictors of mortality were LV ejection fraction $<45 \%$ (Hazard ratio [HR] 3.9, 95\% confidence interval $[\mathrm{CI}]$ 1.52-9.84, $\mathrm{P}=0.004)$ and impaired $\mathrm{RV}$ ejection fraction (HR 2.6, 95\%CI 1.04-6.38, $\mathrm{P}=0.04$ ). The presence of LGE did not predict mortality (HR 1.05, 95\%CI 0.34-3.16, $\mathrm{P}=0.94)$.

\section{Conclusions}

This is, to the best of our knowledge, the largest cohort of patients with scleroderma to have undergone CMR. In this selective cohort, cardiovascular abnormalities on CMR are detectable in the majority $(81 \%)$ of patients with scleroderma and breathlessness and/or other cardiac symptoms. Significant LV dysfunction was the strongest CMR predictor of mortality. Presence of LGE did not predict mortality. 
Table 1 Demographic data and CMR characteristics of 124 patients with symptomatic scleroderma.

\begin{tabular}{|c|c|c|}
\hline Clinical and CMR characteristics & Number (of $n=124$ ) & Percentage (\%) \\
\hline Age & 55 & - \\
\hline$M: F$ & $56: 70$ & $45 \%$ male, $55 \%$ female \\
\hline Patients with at least one cardiac abnormality & 100 & 83 \\
\hline Thinned LV myocardium & 8 & 5 \\
\hline LV dilatation & 24 & 19 \\
\hline LV wall motion abnormality & 40 & 32 \\
\hline LVH & 31 & 25 \\
\hline Raised LV mass index & 23 & 19 \\
\hline Reduced LV long axis fx & 37 & 30 \\
\hline $\mathrm{LV} E F<45 \%$ & 15 & 12 \\
\hline RV dilatation & 30 & 24 \\
\hline Reduction in RV EF & 25 & 20 \\
\hline $\mathrm{RVH}$ & 22 & 22 \\
\hline Reduced RV long axis function & 22 & 17 \\
\hline Pericardial effusion & 20 & 16 \\
\hline LA enlargement (>moderate) & 27 & 22 \\
\hline RA enlargement (>moderate) & 29 & 23 \\
\hline Dilated PA & 45 & 36 \\
\hline Increased signal on T2-STIR & 1 & $<1 \%$ \\
\hline Late gadolinium enhancement & 26 & 21 \\
\hline Patients with only 1 cardiovascular abnormality on CMR & 16 & 13 \\
\hline Patients with 2 cardiovascular abnormalities on CMR & 17 & 13 \\
\hline Patients with 4 or more cardiovascular abnormalities on CMR & 57 & 46 \\
\hline
\end{tabular}

$\mathrm{CMR}=$ cardiac magnetic resonance, $\mathrm{LV}=$ =eft ventricle, $\mathrm{RV}=$ right ventricle, $\mathrm{EF}=$ =jection fraction, $\mathrm{Ml}=$ mass index, $\mathrm{LVH}=$ left ventricular hypertrophy, $\mathrm{LA}=\mathrm{left}$ atrium, $\mathrm{RA}$ right atrium, PA=pulmonary artery, T2-STIR=Short Tau Inversion Recovery.

\section{Funding}

\section{NA.}

\section{Author details}

${ }^{1}$ CMR Unit, Royal Brompton Hospital, London, UK, London, UK. ${ }^{2}$ Pulmonary

hypertension unit, Royal Free Hospital, London, UK.

Published: 30 January 2013

doi:10.1186/1532-429X-15-S1-P160

Cite this article as: Natarajan et al:: Prognostic significance of ventricular

function and late gadolinium enhancement on CMR in symptomatic

patients with scleroderma. Journal of Cardiovascular Magnetic Resonance

2013 15(Suppl 1):P160

Submit your next manuscript to BioMed Central and take full advantage of:

- Convenient online submission

- Thorough peer review

- No space constraints or color figure charges

- Immediate publication on acceptance

- Inclusion in PubMed, CAS, Scopus and Google Scholar

- Research which is freely available for redistribution

Submit your manuscript at www.biomedcentral.com/submit
C Biomed Central 